\title{
Ionospheric Responses to the July 15 - 16, 2000 Magnetic Storm around Geographic Longitude $121^{\circ} \mathrm{E}$
}

\author{
Yu-Jung Chuo ${ }^{1,{ }^{*}}$, Chien-Chih Lee ${ }^{2}$, Jann-Yenq Liu ${ }^{3}$, and Kenro Nozaki ${ }^{4}$ \\ ${ }^{1}$ Department of Commercial Technology and Management, Ling-Tung University, Taichung 408, Taiwan, ROC \\ ${ }_{2}^{2}$ General Education Center, Ching-Yun University, Chung-Li 320, Taiwan, ROC \\ ${ }^{3}$ Institute of Space Science and Center for Space and Remote Sensing Research, National Central University, \\ Chung-Li 320, Taiwan, ROC \\ ${ }^{4}$ Antarctic Research Office, National Institute of Information and Communications Technology, Tokyo, Japan
}

Received 27 November 2006, accepted 17 August 2007

\begin{abstract}
This study presents observed behavior of ionospheric responses using vertical total electron contents (VTEC) and NmF2. The data were collected from global positioning system (GPS) networks and ionosondes around the geographic longitude of $121^{\circ} \mathrm{E}$ from mid- to low-latitudes for the severe magnetic storm on 15 July 2000 . The results show that the severe magnetic storm caused significant density depletion and a G-condition occurrence in the western Pacific region on $15-16$ July 2000. The G-condition is observed on the ionograms at Chung-Li station around 2330 UT on July 15. Furthermore, the variation of the F-peak height $(\mathrm{HmF} 2)$ at Cebu indicates that a zonal electric field produced an upward drift and enhanced the fountain effect from 1000 UT on July 15 . The observation of a G-condition indicates that a storm-induced neutral-wind circulation was the main cause of compositional change; i.e., an increase in the $\mathrm{N}_{2} / \mathrm{O}$ ratio and its associated loss coefficients that produced a negative storm phase along the chain of geographic longitude $121^{\circ} \mathrm{E}$.
\end{abstract}

Key words: Equatorial ionosphere, Magnetic storm, GPS, G-condition

Citation: Chuo, Y. J., C. C. Lee, J. Y. Liu, and K. Nozaki, 2008: Ionospheric responses to the July 15-16, 2000 magnetic storm around geographic longitude $121^{\circ}$ E. Terr. Atmos. Ocean. Sci., 19, 425-432, doi: 10.3319/TAO.2008.19.4.425(AA)

\section{INTRODUCTION}

Geomagnetic storms change peculiarly in a geomagnetic field as a result of the impact of solar wind particles with increased speeds and/or densities in the Earth's magnetosphere. Energy inputs from magnetospheric disturbances to the upper atmosphere cause enhanced electric fields, currents, and energetic particle precipitation. Storm energy deposition at high latitudes generates thermospheric heating and causes global scale changes in thermospheric general circulation. To a great extent, physics-related mechanisms correspond to disturbance dynamo electric fields, thermospheric winds, and neutral composition change (Rishbeth 1991; Fejer and Scherliess 1995; Prölss 1995; Scherliess and Fejer 1997; Lee et al. 2002).

Following a solar flare event on July 14, a great geomagnetic storm occurred on 15 July 2000. The AE index

\footnotetext{
$\overline{* \text { Corresponding author }}$

E-mail:yjchuo@mail.ltu.edu.tw
}

shows an enhancement, exceeding $1000 \mathrm{nT}$, recorded at 1000 UT on 15 July 2000. The AE index continued to increase after 1000 UT with several blasts. Under this prevailing condition, the Dst index showed a sudden decrease to $-300 \mathrm{nT}$ at about $2100 \mathrm{UT}$ on July 15 . Basu et al. (2001) suggested that the enhancement in the AE index probably initiated the ionospheric disturbance dynamo, which started at around 1000 UT on July 15 , and the effect continued for about $10 \mathrm{hr}$ when the IMF Bz turned southward and caused a prompt penetration of electric field into the equatorial ionosphere associated with a sudden decrease in SYM-H around 1500 UT on July 15. Furthermore, horizontal neutral winds expanded to lower latitudes and led thermospheric composition change which is induced by Joule heating at high-latitudes during magnetic storms (Kil et al. 2003). Under these conditions, an interesting feature was clearly seen in the ionograms, namely, the "G-condition", after the commencement of the geomagnetic storm on July 15 . The development of G condi- 
tion, connected with the intensification of magnetic activity, appears to be related to a process associated with the formation of negative ionospheric disturbances on July 16. The ionospheric F-region G-condition is observed on ionograms, when the critical frequency of the F2-layer drops below that of the F1-layer (King 1962). The formation of this phenomenon is either by a decrease in the densities of $\mathrm{O}^{+}$, or by an increase in the densities of molecular ions (Buonsanto 1990; Oliver 1990; Fukao et al. 1991; Pavlov and Buonsanto 1998; Pavlov and Foster 2001). These papers suggest that change in $[\mathrm{O}],\left[\mathrm{N}_{2}\right],\left[\mathrm{O}_{2}\right]$ and plasma drift velocity, as well as the effects of the perpendicular component of the electric field on electron density, and the effects of vibrationally excited $\mathrm{N}_{2}$ and $\mathrm{O}_{2}$ on electron density are important factors that control G-condition formation in the ionosphere.

In the paper, we discuss the use of GPS data to investigate the response of the ionosphere to the 15 July 2000 magnetic storm. During the storm period, TEC (Total Electron Content) observations were obtained only for the $121^{\circ} \mathrm{E}$ geographic longitude sector from mid-latitudes to the equator. Additionally, we compare observed diurnal variations of $\mathrm{NmF} 2, \mathrm{HmF} 2$, and ionograms to explain ionospheric responses observed during the period of the magnetic storm in the western Pacific region.

\section{EXPERIMENT SET-UP}

In this work, two data sets were used to examine ionospheric responses along the geographic longitude of $121^{\circ} \mathrm{E}$ for at storm occurrence on 15 - 16 July 2000. TEC data were derived from the GPS network: SHAO (geographic $31.05^{\circ} \mathrm{N}, 121.12^{\circ} \mathrm{E}$ ), YMSM (geographic $25.17^{\circ} \mathrm{N}, 121.57^{\circ} \mathrm{E}$ ), KDNM (geographic $21.95^{\circ} \mathrm{N}, 120.8^{\circ} \mathrm{E}$ ), and PIMO (geographic $14.6^{\circ} \mathrm{N}, 121.1^{\circ} \mathrm{E}$ ); and ionograms recorded by the Chung-Li (geographic $24.9^{\circ} \mathrm{N}, 121^{\circ} \mathrm{E}$ ) and Cebu (geographic $10.3^{\circ} \mathrm{N}, 123.9^{\circ} \mathrm{E}$ ) ionosondes (as shown in Fig. 1 and Table 1).

By combining all the data recorded by the GPS network receivers, the vertical total electron contents (VTEC) data covered an area of $3-35^{\circ} \mathrm{N}$ and $115-125^{\circ} \mathrm{E}$ (the area demarcated by the bold lines of Fig. 1). We further constructed the diurnal latitude-time-TEC (LTT) plots to describe large scale variations of the ionosphere in the region.

The VTEC were derived from GPS signals (e.g., Liu et al. 1996). In the GPS system, each satellite transmits signals at two frequencies ( $\mathrm{f} 1=1575.42 \mathrm{MHz}$ and $\mathrm{f} 2=1227.60 \mathrm{MHz}$ ). Since the ionosphere is a dispersive medium, scientists are able to evaluate ionospheric effects by measuring the modulations of carrier phases and phase codes recorded by dual-frequency receivers (Sardon et al. 1994; Leick 1995; Liu et al. 1996). Based on the Appleton formula, the phase refractive index in the ionosphere is a function of the radio wave frequency, plasma frequency (electron density), colli-

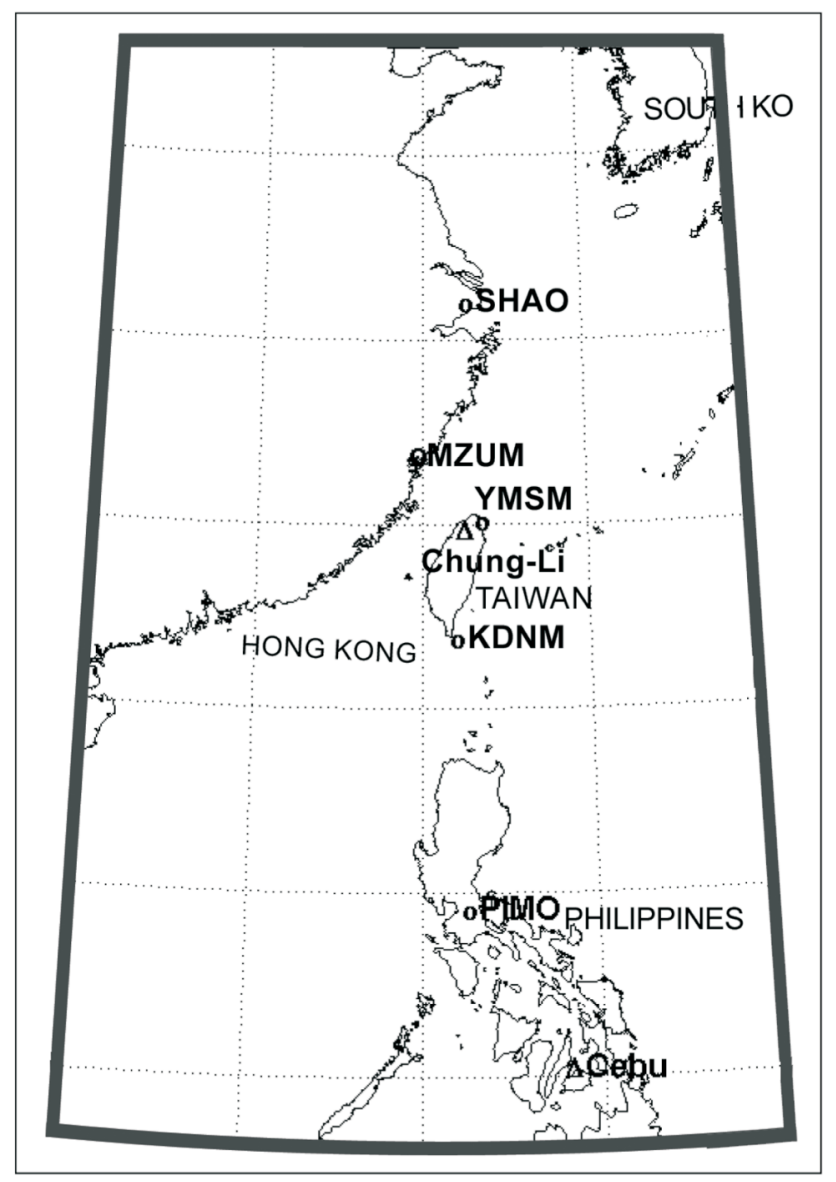

Fig. 1. The locations of digisondes (remark triangle) and GPS receivers (circle).

Table 1. Observation sites.

\begin{tabular}{cccccc}
\hline Site name & \multicolumn{2}{c}{ Geographic coordinates } & \multicolumn{2}{c}{ Geomagnetic coordinates } \\
\hline Chung-Li & $24.9^{\circ} \mathrm{N}$ & $121.0^{\circ} \mathrm{E}$ & \multicolumn{1}{c}{$14.9^{\circ} \mathrm{N}$} & $192.0^{\circ} \mathrm{E}$ \\
Cebu & $10.3^{\circ} \mathrm{N}$ & $123.9^{\circ} \mathrm{E}$ & $0.42^{\circ} \mathrm{N}$ & $195.4^{\circ} \mathrm{E}$ \\
SHAO & $31.1^{\circ} \mathrm{N}$ & $121.1^{\circ} \mathrm{E}$ & $21.0^{\circ} \mathrm{N}$ & $191.8^{\circ} \mathrm{E}$ \\
YMSM & $25.2^{\circ} \mathrm{N}$ & $121.6^{\circ} \mathrm{E}$ & $15.2^{\circ} \mathrm{N}$ & $192.5^{\circ} \mathrm{E}$ \\
KDNM & $21.9^{\circ} \mathrm{N}$ & $120.8^{\circ} \mathrm{E}$ & $11.9^{\circ} \mathrm{N}$ & $191.9^{\circ} \mathrm{E}$ \\
PIMO & $14.6^{\circ} \mathrm{N}$ & $121.1^{\circ} \mathrm{E}$ & $4.6^{\circ} \mathrm{N}$ & $192.5^{\circ} \mathrm{E}$ \\
\hline
\end{tabular}


sion frequency, and magnetic field strength. Since the frequencies of the GPS signals are much higher than the plasma frequency, ionospheric total electron content along the light-of-sight, TEC' in el $\mathrm{m}^{-2}$, between satellite $\mathrm{T}_{\mathrm{x}}$ and ground based receiver $\mathrm{R}_{\mathrm{x}}$ can be expressed as

$d_{\text {ion }}=s^{\prime}-s_{0}=\int_{R_{x}}^{T_{x}}(n-1) \cdot d l=\frac{40.3}{f^{2}} \int_{R_{x}}^{T_{x}} N \cdot d l=\frac{40.3}{f^{2}} T E C^{\prime}$

$\mathrm{VTEC}=T E C^{\prime} \times \cos \chi$

where $d_{i o n}$ is the ionospheric effects; $s_{0}$ is the true distance between the receiver and satellite; $s^{\prime}$ is the virtual distance between the receiver and satellite; $N$ denotes the electron density in $\mathrm{el} \mathrm{m}^{-3} ; n$ denotes the refractive index; and $f$ and $f_{N}$ represent the radio wave and plasma frequencies in $\mathrm{Hz}$, respectively. The $l$-axis represents the receiver-to-satellite direction. $\chi$ is the angle of indication at the sub-ionospheric point of a ray from the satellite to the ground receiver.

Ionograms produced by ionosondes are records that show variations in the virtual height of radio wave reflections from the ionosphere as a function of the radio frequency. based on the magneto-ionic theory, thee are usually two traces, that appear on ionograms - O- and X-mode (for examples, see Budden 1985). Plasma frequency is equal to the vertically reflected O-mode frequency. The greatest frequency foF 2 on an $\mathrm{O}$-mode trace is considered to be the penetration (or largest) plasma frequency (or density) of the ionosphere. The F-peak density (NmF2) is derived from the F2-layer critical plasma frequency (foF2) by the following relationship:

$N m F 2=1.24(f o F 2)^{2} \times 10^{10} \mathrm{el} \mathrm{m}^{-3}$

where $f_{0} F 2$ is in $\mathrm{MHz}$.

The height of the F-peak (HmF2) was estimated by the POLAN program (Titheridge 1995).

\section{RESULTS AND DISCUSSIONS}

At midday on 15 July 2000, an extreme geomagnetic storm in a geomagnetic field was observed. Figure 2 shows the Kp index [panel (a)], Dst index [panel (b)], and auroral electrojet (AE) index [panel (c)] during the storm. Following a coronal mass ejection on 14 July 2000, an enhancement in the AE index exceeding $1000 \mathrm{nT}$, was recorded at $1000 \mathrm{UT}$ on 15 July 2000. The AE index continued to increase after 1000 UT with several bursts in the energy injection rate. Under these conditions, a sudden decrease in Dst value to $-300 \mathrm{nT}$ was recorded between 2100 - 2400 UT. It was noted that the sudden storm commencement (SSC) of this storm occurred at 1500 UT on July 15, the storm main phase started at $1930 \mathrm{UT}$, and the recovery phase started around 2100 UT.

To examine the storm-time ionospheric response, widearea TEC maps were generated using the GPS data collected from SHAO, YMSM, KDNM, and PIMO ground receivers. Figure 3 shows the latitude-time-TEC (LTT) plot during 15 17 July 2000. The LTT map shows clear local time dependence of the ionospheric storm. A severe decrease in the VTEC from mid-latitudes to the dip equator was observed during the daytime on July 16. Moreover, the TEC values of the EIA crest on July 16, in comparison to those on July 15, decreased by $10 \mathrm{TECu}\left(1 \mathrm{TECu}=10^{16} \mathrm{el} \mathrm{m}^{-2}\right)$. Meanwhile, the location of the EIA crest moved southward (toward the equator) from geographic latitude $15^{\circ} \mathrm{N}$ to $10^{\circ} \mathrm{N}$ on July 16 and northward to $26^{\circ} \mathrm{N}$ on July 17 , respectively. Figure 4 shows the diurnal variation of the TEC at SHAO, YMSM, KDNM, and PIMO during July 15 - 16. The variation of TEC for the four GPS receivers follows their monthly median values before the SSC onset. After the SSC onset, there is a TEC increase over KDMN and YMSM starting around 1600 UT on July 15, and this phenomenon is also evident over SHAO though the increase was small. This behavior is likely associated with fountain effect intensification due to an eastward electric field penetrating from high-latitudes into the equatorial ionosphere. An apparent TEC depletion was observed at SHAO (65.7\%), YMSM (66.8\%), KDNM (67.5\%), and PIMO (77\%) at 0600 UT (LT
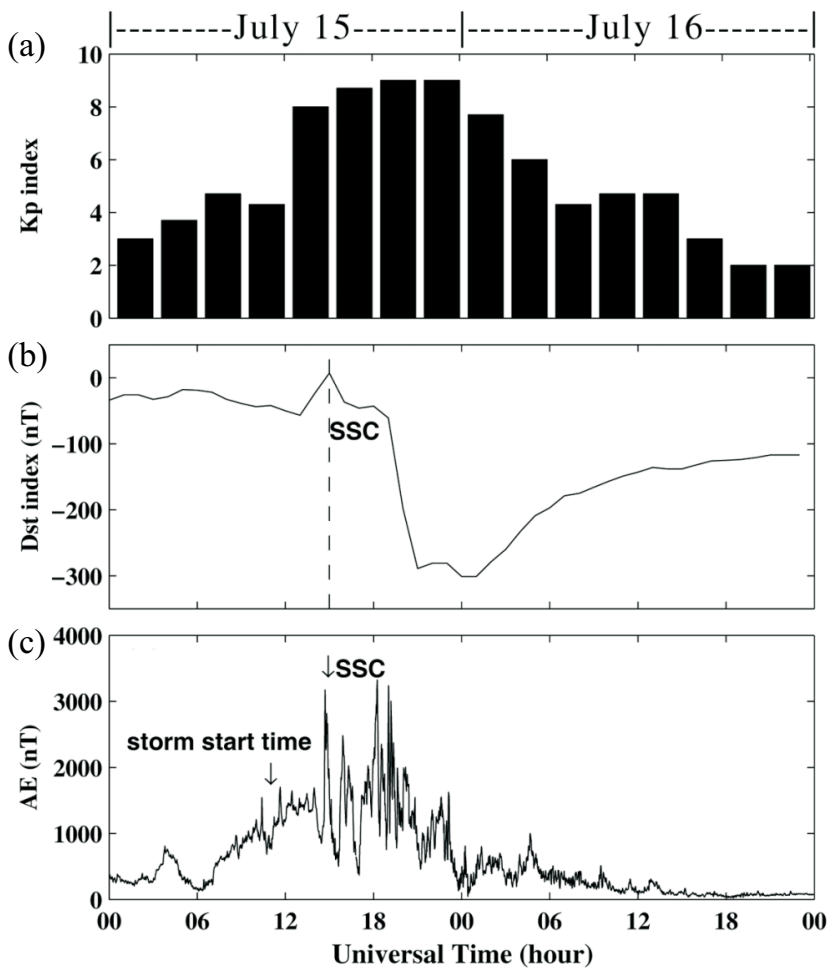

Fig. 2. Geomagnetic indices (a) Kp, (b) Dst, and (c) AE during 15 - 16 July 2000 . 


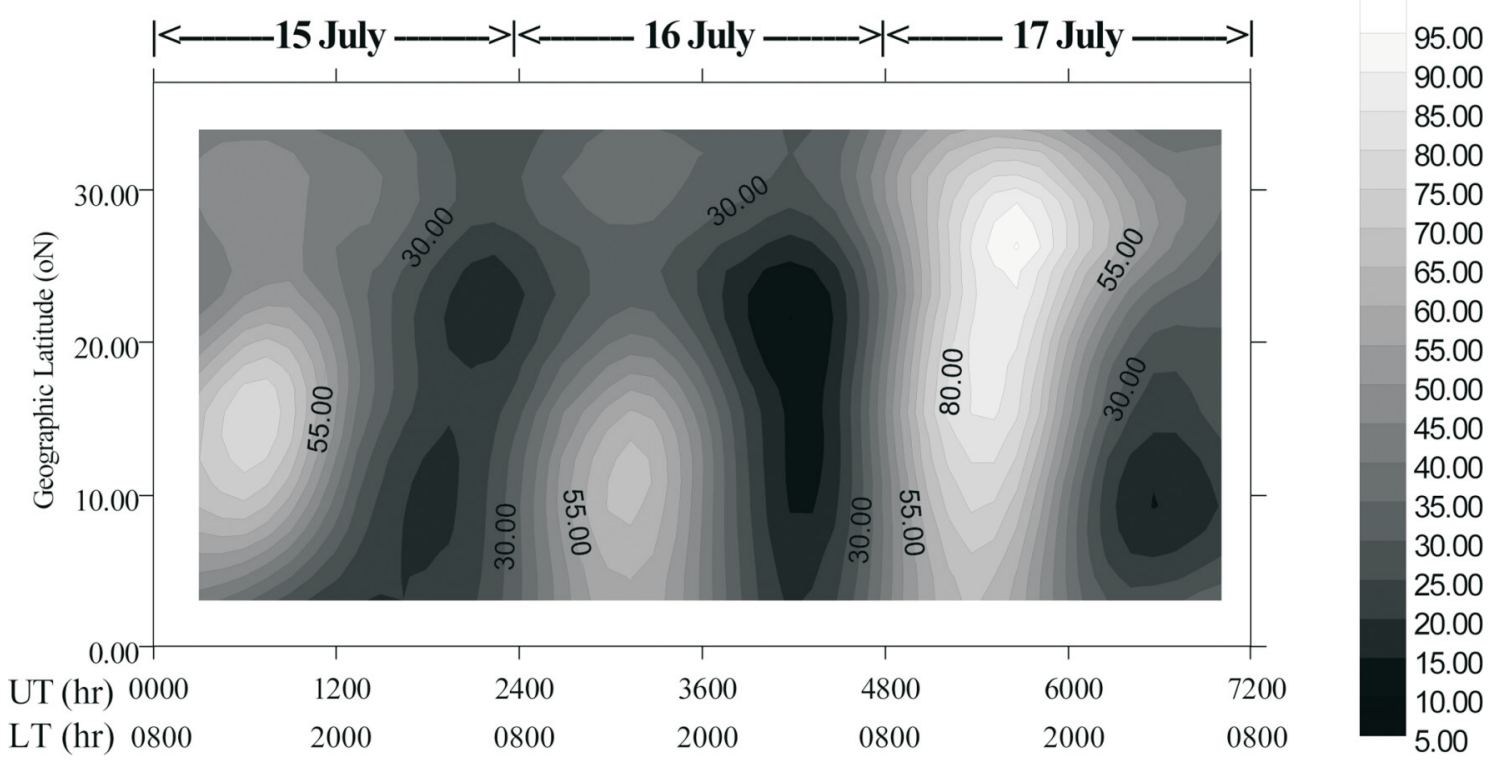

Fig. 3. TEC-Latitude-Time plots examined during 15 - 17 July 2000.

(a)

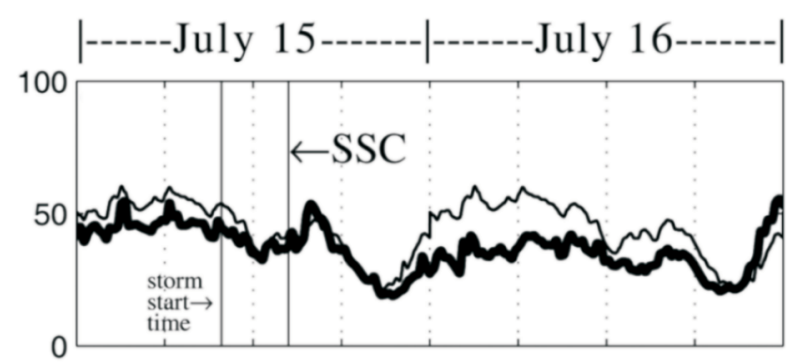

(b)

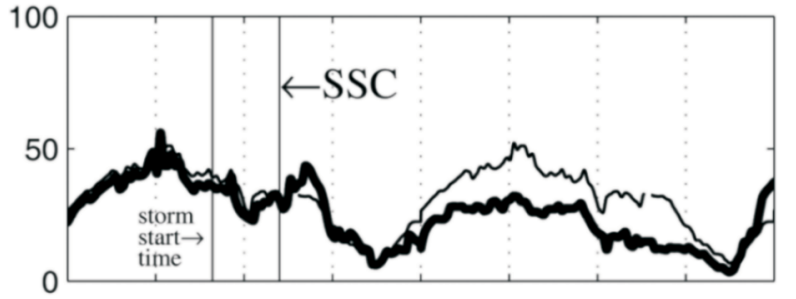

(c)

(d)
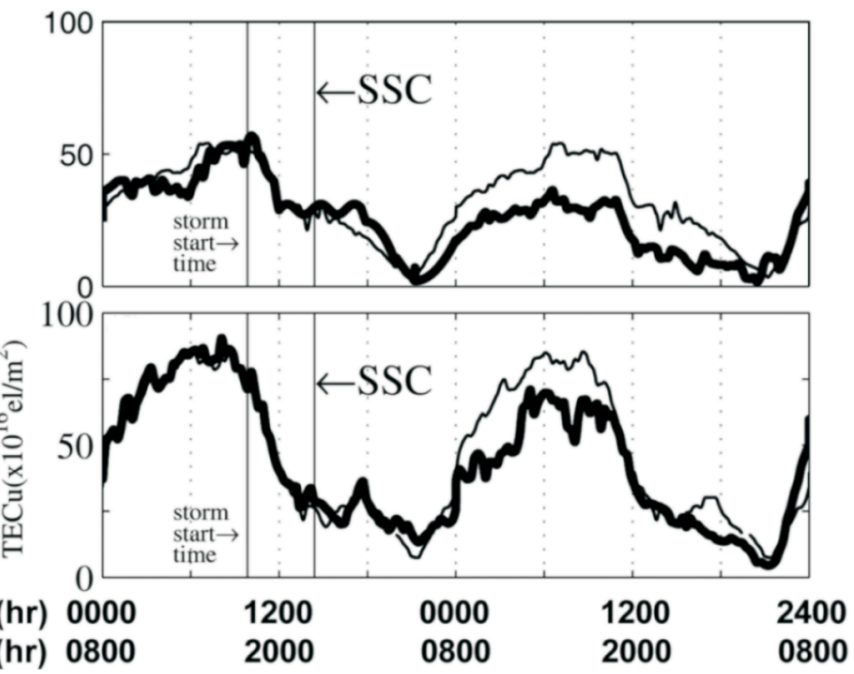

Fig. 4. Vertical TEC (bold line) over (a) SHAO, (b) YMSM, (c) KDNM, and (d) PIMO during $15-16$ July 2000. The thin line represents the median values of July 2000 .
$=\mathrm{UT}+8 \mathrm{~h}$ ) on July 16 and it lasted more than 24 hours. Previous studies (Prölss 1987, 1993; Rishbeth et al. 1987; Titheridge and Buonsanto 1988; Fuller-Rowell et al. 1996; Schlesier and Buonsanto 1999) suggested that a negative storm effect and movement toward the equator of an EIA crest during a storm may be contributed to by: (i) a westward electric field, or (ii) neutral compositional changes, and (iii) poleward winds to levels of greater loss. For understanding possible physical mechanisms involved, we applied ground-based data from ionosondes at Cebu and Chung-Li for analysis.

Figure 5 shows variation in ionospheric parameters and disturbance-drift driven by high-latitude processes during July 15 - 16 at Cebu. The upper panel presents the NmF2 for this period, the center panel shows the $\mathrm{HmF}$, and the lower panel gives the disturbance drifts components derived from the empirical model of Fejer and Scherliess (1997). The circle-line and solid-line represent the disturbance dynamo and prompt penetration drift components in Fig. 5c, respectively. For Figs. 5a-b, the thin solid and thick solid lines represent the monthly median and observed data, respectively. The result shows an increase from 410 to $600 \mathrm{~km}$ in $\mathrm{HmF} 2$ and a decrease in NmF2 simultaneously at 1000 UT (1800 LT) on July 15. Fig. 5c shows that the apparent increase in $\mathrm{HmF} 2$ was caused by the disturbance dynamo drift during this period. The result indicates an eastward electric field occurrence that enhances the equatorial fountain effect so as to make plasma drift out of the equatorial region during the post-sunset period. Moreover, a sharp decrease in HmF2 occurred around 2000 UT (0400 LT) and is accompanied by a decrease in NmF2. This result may have been caused by a westward electric field resulting from a sudden IMF Bz northward 
(a)

(b)
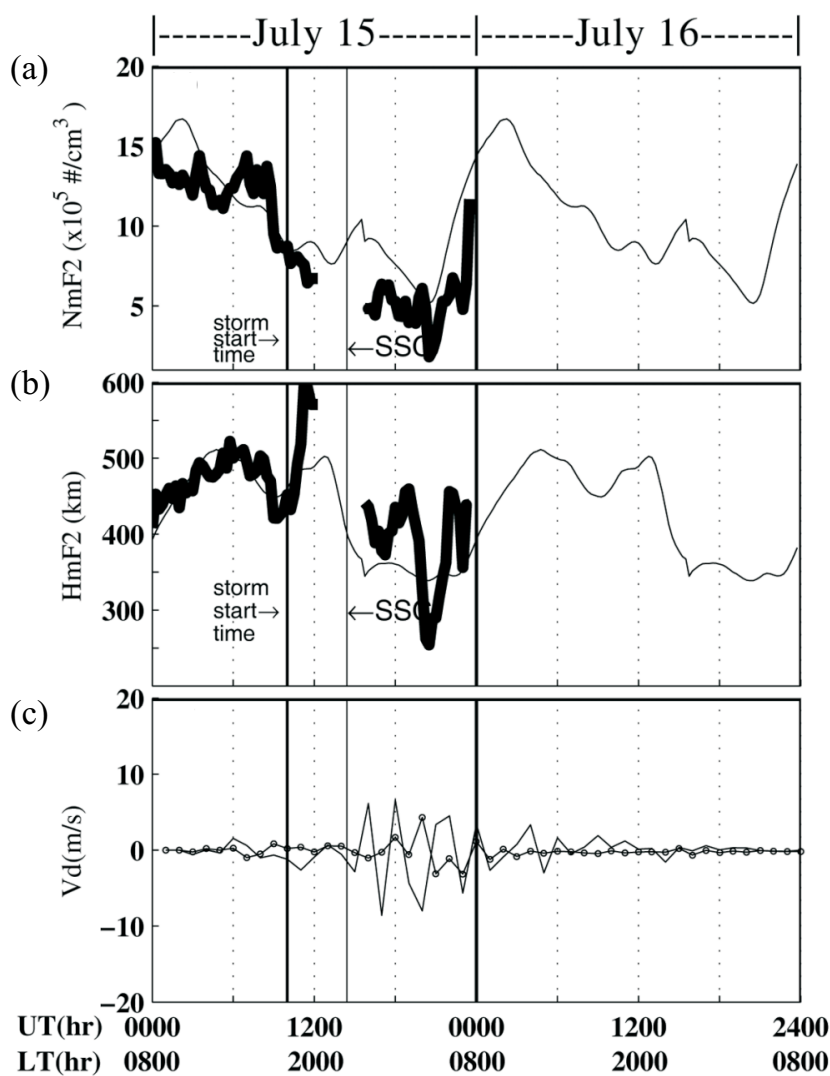

Fig. 5. (a) The F-peak density, NmF2, (bold line), (b) F-peak height, HmF2 (bold line), and (c) prompt penetration (thin solid line) and disturbance dynamo (circle line) drifts observed at Cebu during the period of 15 - 16 July 2000 . The thin line represents the median values of July 2000

movement from a steady southward direction to produce a dusk-to-dawn electric field perturbation. That perturbation could have penetrated the equatorial ionosphere leading the plasma downward to lower altitudes; this would have resulted in increased chemical losses and consequently a decrease in electron density (Kelley et al. 1979). Later, $\mathrm{HmF} 2$ increases again and is associated with a decrease in $\mathrm{NmF}$ 2; this could have been caused by penetration electric fields from high latitudes (Fig. 5c) as AE index enhancement remained and reached up to $2000 \mathrm{nT}$ at that time (Fig. 2c).

Figure 6 shows the same parameters as those in Fig. 5 but for the Chung-Li station. A sharp increase in NmF2 is observed from $1200-1700 \mathrm{UT}(\mathrm{LT}=\mathrm{UT}+8 \mathrm{~h})$ on the $15^{\text {th }}$. After 1700 UT on July 15, the NmF2 decreased by $50-75 \%$ until the end of the $16^{\text {th }}$. Further, HmF2 follows the monthly median values before the SSC onset. Nevertheless, there is a huge increase in the F2-layer from $310-550 \mathrm{~km}$ between 1745 UT on July 15 and 0015 UT on July 16 (Fig. 6b). Meanwhile, an abnormal decrease is observed in $\mathrm{HmF}$, which suddenly drops from $F_{2}$ to $F_{1}$ (lower $250 \mathrm{~km}$ ) region heights (G-condition) from 2330 UT on July 15 to 0015 UT of July 16 . Under these conditions, the ionograms show the (a)

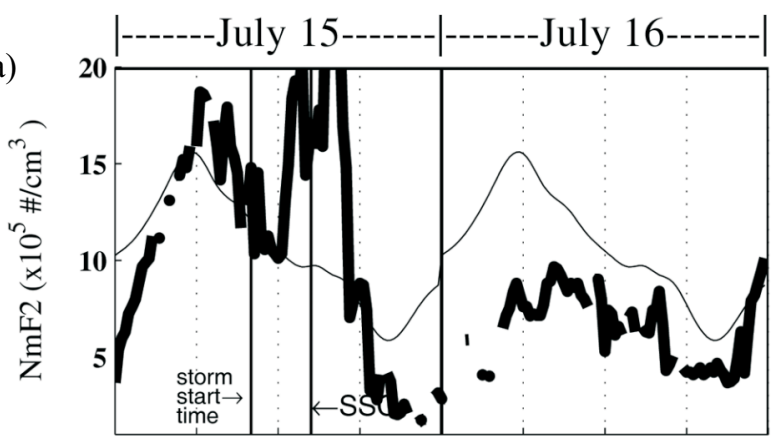

(b)

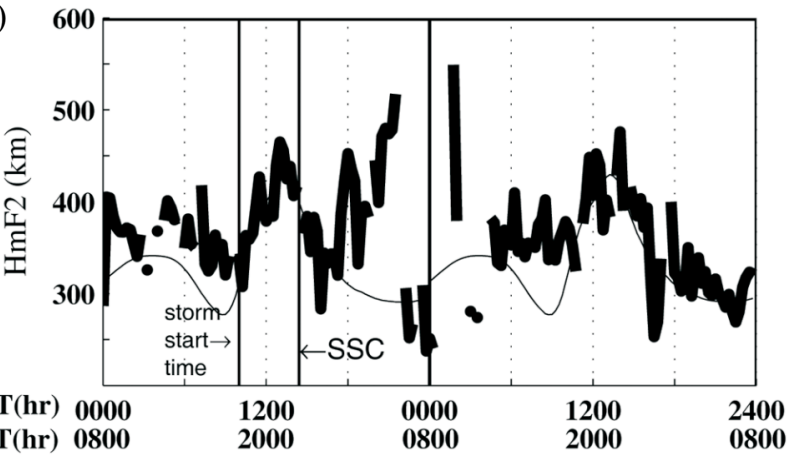

Fig. 6. (a) The F-peak density, NmF2, (bold line) and (b) F-peak height, $\mathrm{HmF} 2$ (bold line) observed at Chung-Li. The thin line represents the median values of July 2000 .

F2-layer appearing at 2300 UT before it then disappears at 2330 UT giving the $\mathrm{G}$-condition (Fig. 7). Therefore, the increase in $\mathrm{NmF} 2$ must be produced by an enhanced fountain effect from the equator, which was triggered by a penetration electric field at 1000 UT on the $15^{\text {th }}$ (Fejer and Scherliess 1997; Basu et al. 2001). Moreover, the decrease in NmF2 is associated with an increase in $\mathrm{HmF} 2$ starting at $1730 \mathrm{UT}$ on the $15^{\text {th }}$. It was caused by a prompt penetration electric field when the IMF $B_{z}$ turned southward. Simultaneously, enhanced thermospheric winds added to the background dayto-night circulation and transported compositional changes to lower latitudes (Fuller-Rowell et al. 1994, 1996; Buonsanto 1999; Pavlov and Foster 2001). This resulted in a decrease in the ratio of atomic oxygen density $[\mathrm{O}]$ to molecular nitrogen $\left[\mathrm{N}_{2}\right]$ and oxygen $\left[\mathrm{O}_{2}\right]$ densities. An increase in the $\mathrm{N}_{2} / \mathrm{O}$ ratio would lead to a decrease in the $\mathrm{NmF} 2$ and TEC and vice versa (Prölss 1987; Rishbeth et al. 1987). This neutral compositional change not only produced the negative storm effect but also created the G-condition, which was observed at the Chung-Li station (Figs. 6, 7). Kil et al. (2003) observed the $\mathrm{O}^{+}$proportion, vertical ion drift velocity, and ion concentration by DMSP satellites F13 and F15; for this an increase in the upward ion drift and smaller $\mathrm{O}^{+}$loss rate was observed at mid- and low-latitudes during 0129 - 0220 UT, respectively. The upward plasma drift lifted the ionization to higher altitudes where the $\mathrm{O}^{+}$loss rate was smaller, and this was compensated for by a smaller production rate due to the decrease in $[\mathrm{O}]$; this created the G-condition and the negative storm phase (Pavlov and Buonsanto 1998; Pavlov and 
(a) 2300UT, 15 July

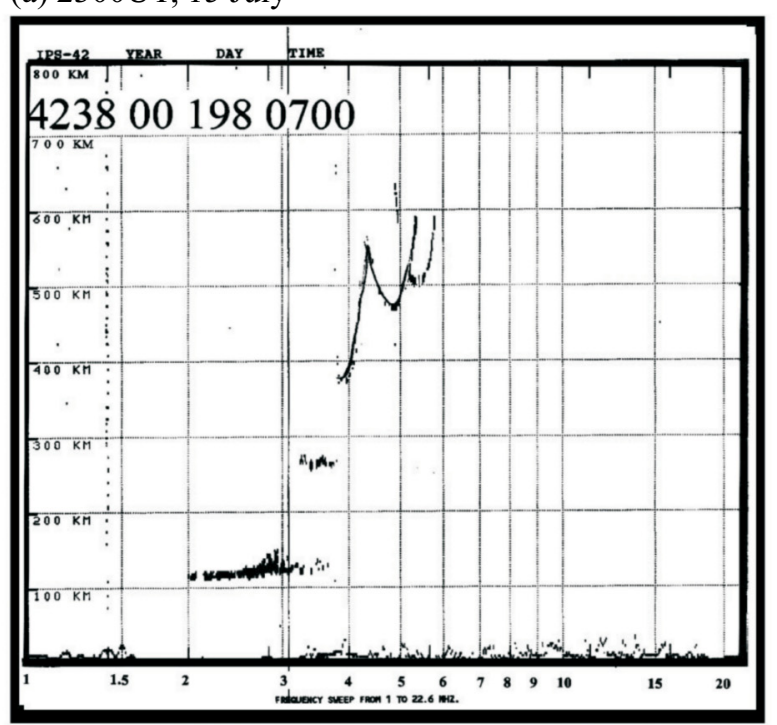

(b) 2315UT, 15 July

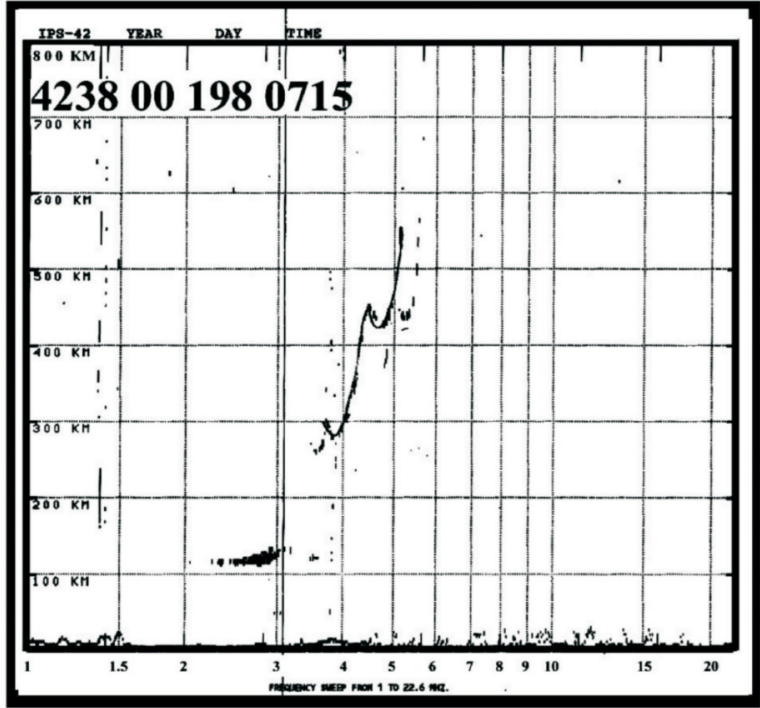

(c) 2330UT, 15 July

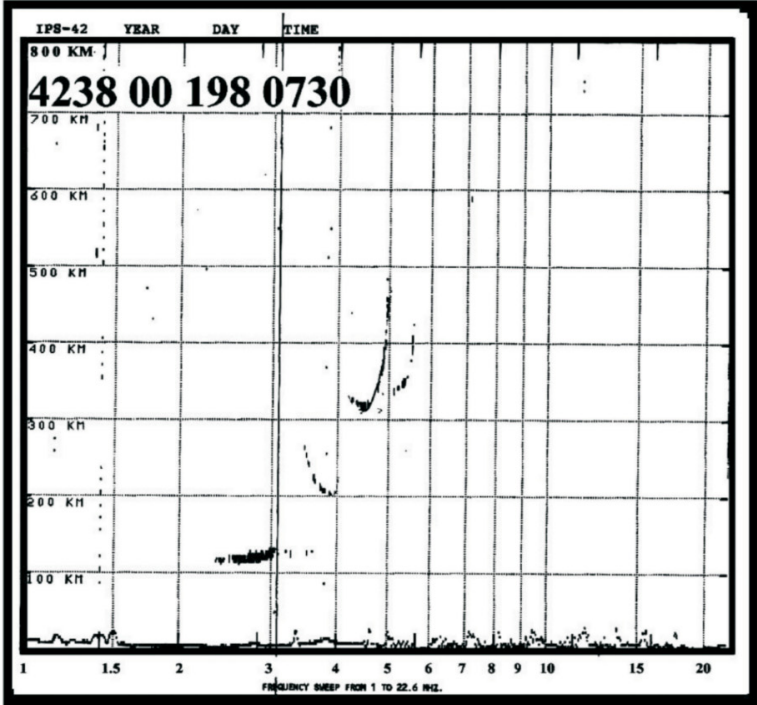

(d) 2345UT, 15 July

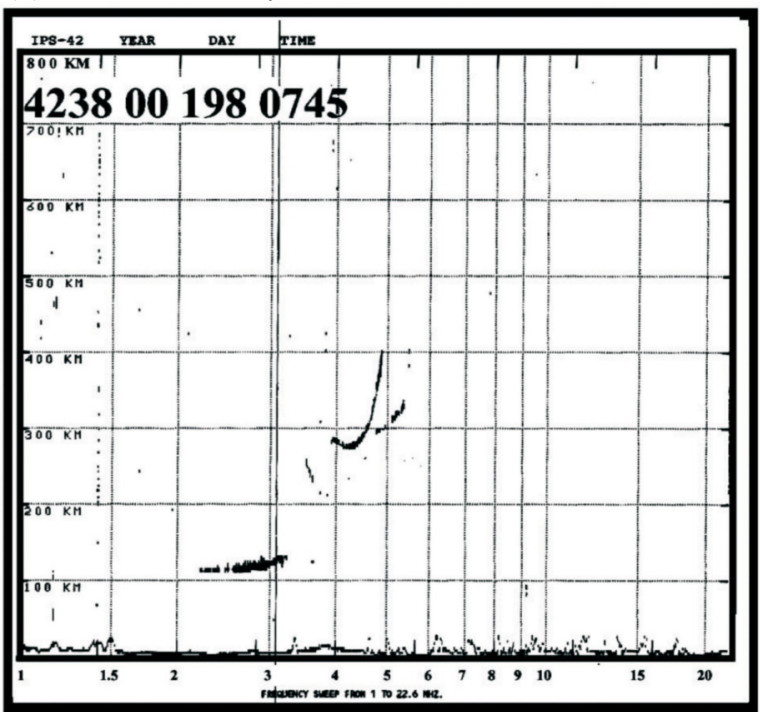

(e) 0000UT, 16 July

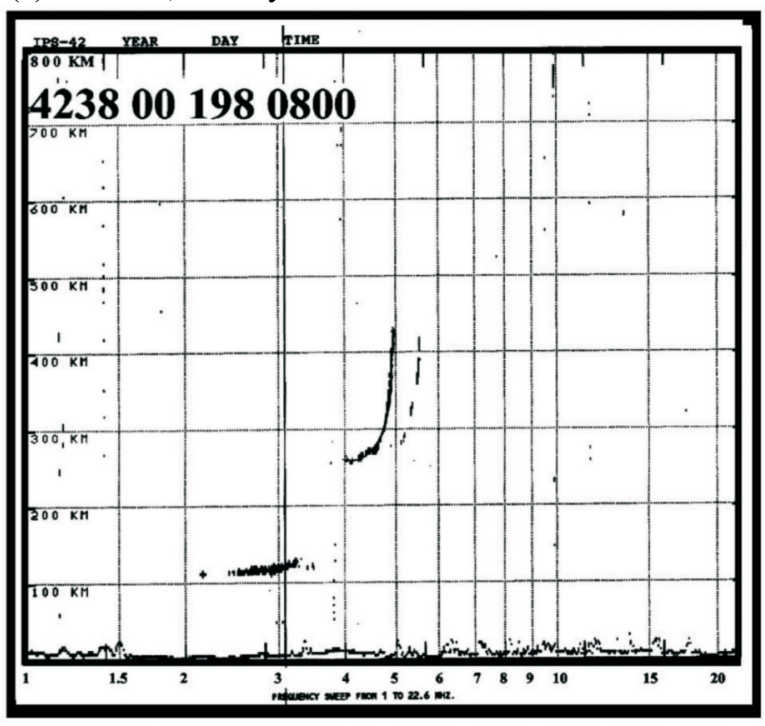

(f) 0015UT, 16 July

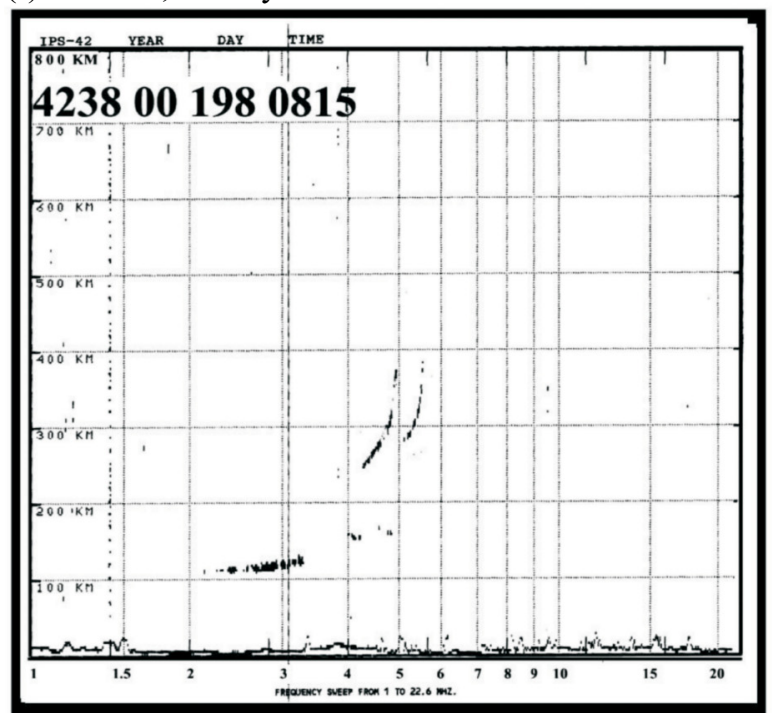

Fig. 7. The ionograms recorded at $0700-0815$ LT on 16 July 2000. 
Foster 2001). This result is in agreement with our observation and explanations.

\section{CONCLUSIONS}

Ionospheric responses during magnetic storms change in complex ways, especially at low latitudes and in equatorial regions. Ionospheric storms are far from fully understood, so case studies are crucial in their understanding. A large geomagnetic storm occurrence on 15 - 16 July 2000 is analyzed using GPS generated TEC data and ionosondes around the $121^{\circ} \mathrm{E}$ longitude at mid- and low latitudes. There were many striking features to the storm, such as a negative storm effect, nighttime enhancements in NmF2, G-condition, and the inhibition of the crest of the equatorial anomaly on 16 July 2000. A summary of the investigations conclusions is as follows:

(1) When the storm started, ionospheric responses show a penetration electric field at the equator; this not only produced an upward plasma drift but also enhanced the equatorial fountain effect (Fig. 5). The enhanced upward drift increased $\mathrm{HmF} 2$, thereby causing a decrease in $\mathrm{NmF} 2$ at Cebu and an increase in $\mathrm{NmF} 2$ after $2 \mathrm{~h}$ at Chung-Li (Fig. 6).

(2) Figures 4, 5, and 6 indicate a prompt eastward electric field penetrating the equatorial ionosphere and equatorial disturbance dynamo electric fields causing ionospheric F-region uplift and electron density depletion. This expanded outward to low latitudes at SSC on July 15.

(3) Figure 3 indicates that the negative storm effect expanded rapidly to the equator and that the development of the equatorial anomaly was inhibited on July 16.

(4) As for the increase in TEC on July 17 (Fig. 3), the anomalous development of the equatorial anomaly may have been caused by changes in neutrals, especially atomic $\mathrm{O}$. If the $\mathrm{O}$ concentration increased significantly at low latitude on July 17, it would have resulted in the equatorial anomaly in TEC.

(5) An ionospheric G-condition was observed on the night of July 15. This suggests enhancements in $\mathrm{N}_{2} / \mathrm{O}$ and $\mathrm{O}_{2} / \mathrm{O}$ occurring. $\mathrm{N}_{2}$ and $\mathrm{O}_{2}$ increased due to upwelling caused by storm-time circulation from high latitudes producing $\mathrm{O}^{+}$and rapid electron depletion at the $\mathrm{F} 2$ layer. Therefore, the negative phase on 16 July 2000 is strongly associated with increasing $\mathrm{N}_{2} / \mathrm{O}$ and $\mathrm{O}_{2} / \mathrm{O}$ ratios. In the paper, our results suggest that except for zonal electric fields, atmospheric compositions could also play an important role during negative storms at low latitudes.

Acknowledgements The authors would like to thank to the Satellite Survey Center, Department of Land Administration, M.O.I. in Taiwan and the international GPS service for geodynamics (IGS) for providing data, and to the Na- tional Geophysical Data Center (NGDC) (www.ngdc.noaa .gov) for providing data of Kp and Dst. YJC was supported by the National Science Council (NSC) grant \#96-2111M-275-001. CCL was supported by the NSC grant \#962119-M-231-001.

\section{REFERENCES}

Basu, S., S. Basu, K. M. Groves, H. C. Yeh, S. Y. Su, F. J. Rich, P. J. Sultan, and M. J. Keskinen, 2001: Response of equatorial ionosphere in the south Atlantic region to the great magnetic storm of July 15, 2000. Geophys. Res. Lett., 28, 3577-3580

Budden, K. G., 1985: The Propagation of Radio Waves. Cambridge University Press, 669 pp.

Buonsanto, M. J., 1990: Observed and calculated F2 peak heights and derived meridional winds and mid-latitudes over a full solar cycle. J. Atmos. Terr. Phys., 52, 223-240.

Buonsanto, M. J., 1999: Ionospheric storms - A review. Space Sci. Rec., 88, 563-601.

Fejer, B. G. and L. Scherliess, 1995: Time dependent response of equatorial ionospheric electric fields to magnetospheric disturbances. Geophys. Res. Lett., 22, 851-854.

Fejer, B. G. and L. Scherliess, 1997: Empirical models of storm time equatorial zonal electric field. J. Geophys. Res., 102, 24047-24056.

Fukao, S., W. L. Oliver, Y. Onishi, T. Takami, T. Sato, T. Tsuda, M. Yamamoto, and S. Kato, 1991: F-region seasonal behaviour as measuremed by the MU radar. J. Atmos. Terr. Phys., 53, 599-618.

Fuller-Rowell, T. J., M. V. Codrescu, R. J. Moett, and S. Quegan, 1994: Response of the thermosphere and ionosphere to geomagnetic storms. J. Geophys. Res., 99, 3893-2914.

Fuller-Rowell, T. J., M. V. Codrescu, R. J. Moett, and S. Quegan, 1996: On the seasonal response of the thermosphere and ionosphere to geomagnetic storms. J. Geophys. Res., 101, 2343-2353.

Kelley, M. C., B. G. Fejer, and C. A. Gonzales, 1979: Explanation for anomalous ionospheric electric fields associated with a northward turning of the interplanetary magnetic field. Geophys. Res. Lett., 6, 301-304.

Kil, H., L. J. Paxton, X. Pi, M. R. Hairston, and Y. Zhang, 2003: Case study of the 15 July 2000 magnetic storm effects on the ionospheric-driver of the positive ionospheric storm in the winter hemisphere. J. Geophys., Res., 108, 1391, doi: 10.1029/2002JA009782.

King, G. A. M., 1962: The ionospheric F region during a storm. Planet. Space Sci., 9, 95-100.

Lee, C. C., J. Y. Liu, B. W. Reinisch, Y. P. Lee, and L. B. Liu, 2002: The propagation of traveling atmospheric disturbances observed during April 6-7, 2000 ionospheric storm in the West Pacific region. Geophys. Res. Lett., 29, 5, doi: 10.1029/2001GL013516.

Leick, A., 1995: GPS Satellite Surveying. John Wiley, New 
York, $560 \mathrm{pp}$.

Liu, J. Y., H. F. Tsai, and T. K. Jung, 1996: Total electron content obtained by using the global positioning system. Terr. Atmos. Ocean. Sci., 7, 107-117.

Oliver, W. L., 1990: Neutral and ion composition changes in the F-region over Millstone Hill during the equinox transition study. J. Geophys. Res., 95, 4129-4134.

Pavlov, A. V. and M. J. Buonsanto, 1998: Anomalous electrondensity events in the quiet summer ionosphere at solar minimum over Millstone Hill. Ann. Geophys., 16, 460469.

Pavlov, A. V. and J. C. Foster, 2001: Model/data comparsion of F region ionospheric perturbation over Millstone Hill during the severe geomagnetic storm of July 15-16, 2000. J. Geophys. Res., 106, 29051-29069.

Prölss, G. W., 1987: Storm-induced changes in the thermospheric composition at middle latitudes. Planet. Space Sci., 35, 807-811.

Prölss, G. W., 1993: Common origin of positive ionospheric storms at middle latitudes and the geomagnetic activity effect at low latitudes. J. Geophys. Res., 98, 5981-5991.

Prölss, G. W., 1995: Ionospheric F-region storms. In: Volland, H. (Ed.), Handbook of Atmospheric Electrodynamics, Vol.
2, CRC Press, Boca Ratin, FL, 195-248.

Rishbeth, H., 1991: F-region storm and thermospheric dynamics. J. Geomag. Geoelectr., 43(Suppl.), 513-524.

Rishbeth, H., T. J. Fuller-Rowell, and D. Rees, 1987: Diffusive equilibrium and vertical motion in the thermosphere during a severe magnetic storm: A computational study. Planet. Sapce Sci., 35, 1157-1165.

Sardon, E., A. Rius, and N. Zarraoa, 1994: Estimation of the transmitter and receiver differential biases and the ionospheric total electron content from global positioning system observations. Radio Sci., 29, 577-586.

Schlesier, A. C. and M. J. Buonsanto, 1999: Observations and modeling of the April 10-12, 1997 ionospheric storm at Millstone Hill. Geophys. Res. Lett., 26, 2359-2362.

Scherliess, L. and B. G. Fejer, 1997: Storm time dependence of equatorial disturbance dynamo zonal electric fields. $J$. Geophys. Res., 102, 24037-24046.

Titheridge, J. E., 1995: Ionogram analysis with the generalized program POLAN. Report UAG-93, World Data Center for Solar-Terrestrial Physics, Washington DC.

Titheridge, J. E. and M. J. Buonsanto, 1988: A comparison of northern and southern hemisphere TEC storm behavior. $J$. Atmos. Terr. Phys., 50, 763-780. 